\title{
Diurnal intraocular pressure variations: an analysis of 690 diurnal curves
}

\author{
Robert David, Linda Zangwill, Daniel Briscoe, Michael Dagan, Ronit Yagev, Yuval Yassur
}

\begin{abstract}
Out of a total of 2272 diurnal curves (DC) of intraocular pressure (IOP) obtained from 1178 patients 690 first curves of the right eye of all patients were analysed. For each DC there were 4-6 IOP readings taken between 8 am and $6.30 \mathrm{pm}$ of the same day. The patients' diagnosis, age, sex, type of IOP lowering medication, diabetes, and the calendar month of the year were recorded. In $40 \%$ of cases the highest IOP was found at the earliest morning measurement with some $65 \%$ of peaks occurring before noon. The lowest IOP measurement showed no specific predilection for any particular time of the day. These findings were true for all diagnosis groups. The mean range of IOP fluctuation during the DC was $5.0 \mathrm{~mm} \mathrm{Hg}$ in normals, $5.8 \mathrm{~mm} \mathrm{Hg}$ in patients with open angle glaucoma (OAG), and $6.8 \mathrm{~mm} \mathrm{Hg}$ in patients with ocular hypertension (OHT). Patients treated with timolol had a lower mean IOP fluctuation range than those on other types of IOP lowering treatment. No association was found between all other parameters examined and the diurnal IOP distribution.
\end{abstract}

Intraocular pressure (IOP) is subject to chronobiological rhythms similar to other physiological values in the human body. IOP measurements during different hours of the day have a well recognised clinical importance which can directly affect the diagnosis and management of the patient with IOP related conditions.

In clinical practice performing diurnal IOP curves (DC) has several indications: (1) in patients with ocular hypertension (OHT) it is essential to obtain baseline IOP levels and monitor the condition, (2) in glaucomatous patients with progressive damage whenever single IOP measurements are within the 'normal' range, and (3) in cases when a suspicious looking optic disc is discovered in patients without apparent IOP elevation.

The information offered to the attending ophthalmologist by the DC (or 'phasing' as some prefer to call it) as opposed to the single IOP reading is manifold:

(1) it gives a better indication of the IOP levels since the solitary reading taken in the office may not reveal the peak IOP level;

(2) it identifies the time of the day when the peak IOP occurs;

(3) it clarifies the range of IOP fluctuation during the examination period.

Each of these answers provides valuable data which will ensure better understanding and management of the individual's disease process.
For these reasons the performing of diurnal IOP examinations has been widely practised in glaucoma clinics for many years and the literature is abundant with information on the subject. There is general agreement with respect to the range of IOP fluctuation. It has been shown that this does not usually exceed $3-6 \mathrm{~mm} \mathrm{Hg}$ in normal eyes ${ }^{12}$ but can reach $10 \mathrm{~mm} \mathrm{Hg}$ and more in glaucoma patients before initiating treatment. ${ }^{1-4}$

There are conflicting reports in the literature however as to the time of the day at which the peak IOP occurs during the DC. Some reports found the peak IOP in the morning, ${ }^{25}$ while others have shown that it may occur at any time during the day. ${ }^{36}$ All these studies have several drawbacks: they were performed mostly on patients in hospital, the majority employed the Schiotz tonometer for measuring IOP and the number of eyes studied varied from 20 to 500 .

The objective of this study is to evaluate the distribution of IOP levels during the day during those hours that it is customary to examine ambulatory patients - and its association with several parameters including diagnosis, type of treatment, and demographic characteristics.

\section{Clinical material}

The Glaucoma Clinic of the Soroka University Hospital is a central referral service for the Sick Fund Health Insurance covering some $90 \%$ of a population of more than 300000 people. All persons who need a DC evaluation are referred to this clinic. DCs are performed on most new referrals and whenever indicated in the case management. Untreated ocular hypertensives have a DC examination every other year.

The present study is based on the information collected from the DCs performed at the Glaucoma Clinic under similar conditions between 1979 and 1989 .

Patients scheduled for DC examination were invited to the outpatient clinic at 7.45 am for IOP testing every 2 hours until at least $6 \mathrm{pm}$. At the time the appointment for the $\mathrm{DC}$ was given the patients were instructed to take their morning

Table 1 Timetable for six IOP measurements during the diurnal curve

Time of reading

early morning ( $7.45 \mathrm{am}$ until $9.00 \mathrm{am})$ mid-morning $(9.45 \mathrm{am}$ until $11.30 \mathrm{am})$

mid-morning (9.45 am until 11.30

mid-day (11.30 am until $2.00 \mathrm{pm}$ )

early afternoon $(2.00 \mathrm{pm}$ until $4.00 \mathrm{pm})$

mid-afternoon (4.00 pm until $5.30 \mathrm{pm})$

evening (5.30 pm until $7.00 \mathrm{pm}$ ) 
Table 2 Number of IOP measurements on each diurnal curve

\begin{tabular}{lrc}
\hline & $n$ & $(\%)$ \\
\hline Six readings & 873 & $(38 \cdot 4)$ \\
Five readings & 1209 & $(53 \cdot 2)$ \\
Four readings & 190 & $(8 \cdot 4)$ \\
Total diurnal curves & 2272 & \\
\hline
\end{tabular}

medication(s) and to bring them along on the day of their appointment. Patients arriving for the DC after 9 am were not examined but given a new appointment.

There were six scheduled IOP readings for the DC as shown in Table 1.

The first four IOP measurements were taken in the outpatient clinic, usually by the resident on duty for the following 24 hours who was also taking the last two IOP measurements for the DC in the inpatient ward. All IOP measurements were performed with the Goldman applanation tonometer attached to the slit-lamp.

All DCs were recorded on a chart covered with millimetric paper, with the hours of the day marked on the abscissa and the IOP on the ordinate. Each chart accommodates both eyes and it bears the patient's name, ID number, and the date of the DC. After completing the DC the charts were reviewed by a glaucoma subspecialist and consequently returned to the glaucoma file for safekeeping.

For the purpose of the present study all glaucoma files were reviewed and the following data were recorded if a DC was present:

(1) demographic information: age, sex, date of DC

(2) for diabetic patients, whether insulin treated or not

(3) the patient's diagnosis in the glaucoma clinic

(4) the IOP and the time of each measurement

(5) the type of treatment the patient was receiving; four categories of treatments were recorded:

(i) no treatment

(ii) topical $\beta$ blocker alone

(iii) topical $\beta$ blockers and other IOP lowering drugs

(iv) any IOP lowering medication(s) except $\beta$ blocker. The $\beta$ blocker used throughout the study period was timolol.

Under the diagnosis 'aphakic/pseudophakic' were included patients who had no increased IOP before their cataract surgery. For patients with more than one DC in the file each curve was recorded.

Patients who completed at least four IOP measurements on their DC were included in the study. The results are presented in terms of patients, using the findings of the right eyes only, after ascertaining that the results were similar in both eyes.

Unless otherwise stated the first DC of each patient was used in each analysis so that each curve can be considered an independent event. If more than one curve for each patient had been included then persons with more than one curve would be disproportionately represented in the analyses.

Associations and statistical significance were calculated using the $t$ test, analysis of variance, and $\chi^{2}$ methods.

\section{Results}

The review of more than 1400 glaucoma files in the clinic identified 1178 persons who had completed 2272 diurnal curves; $650(55 \%)$ were men and $528(45 \%)$ were women. The mean age of persons in the study excluding those with a diagnosis of developmental glaucoma was $62 \cdot 2$ (SD 12.1) years.

Of the 2272 DCs $38 \cdot 4 \%$ had completed all six pressure measurements and $53 \cdot 2 \%$ had five IOP values. Only $8 \cdot 4 \%$ had four measurements (Table 2).

The number of DCs for each individual is shown in Table 3.

Table 4 displays the distribution of the DCs by diagnosis for each eye separately. The DCs diagnosed as 'other' included developmental, secondary, traumatic, and low tension glaucoma. Since the number of cases in each of these subgroups is small they were not included in the analysis of the results by diagnosis. After excluding these cases 690 first DCs of right eyes were left for analysis.

In Table 5 the distribution of the peak IOP reading in the various diagnostic groups at the six different time checks is presented for the 690 DCs. Overall $41 \%$ of peaks were found on the first, earliest IOP measurement, in the morning and another $24 \%$ at the second, mid-morning examination, while only $2 \%$ exhibited the peak IOP in the last, evening IOP reading. This trend remained consistent in each diagnostic group. These results are presented graphically in Figure 1.

Contrary to the peaks which showed the clear tendency to present in the morning hours the lowest IOP values were scattered at all times of the day regardless of the diagnostic groups (see Table 6 and Fig 2). This pattern of peaks and troughs was also found when the 259 patients with two curves and the 90 patients with three curves were evaluated separately.

The mean IOP was found to be highest in the morning hours with a steady decline throughout the day. This trend was consistent in each diagnostic group and is presented in Figure 3.

The mean range of IOP fluctuation (highest

Table 3 Number of patients, eyes, and diurnal curves

\begin{tabular}{lcc}
\hline Number of DCs & $\begin{array}{l}\text { Patients } \\
(\boldsymbol{n})\end{array}$ & $\begin{array}{l}\text { Eyes } \\
(\boldsymbol{n})\end{array}$ \\
\hline 1 & 767 & 1483 \\
2 & 269 & 517 \\
3 & 90 & 171 \\
4 or more & 52 & 101 \\
Total DCs & 1178 & 2272 \\
\hline
\end{tabular}

Table 4 Number of diurnal curves by diagnosis

\begin{tabular}{lrcc}
\hline & Total & Right eye & Left eye \\
\hline Normal & 206 & 100 & 106 \\
Open angle glaucoma (OAG) & 482 & 250 & 232 \\
Ocular hypertension(OHT) & 1094 & 533 & 561 \\
Chronic angle closure(CACG) & 253 & 127 & 126 \\
Aphakic/pseudophakic & 92 & 51 & 41 \\
Other & 145 & 77 & 68 \\
Total & 2272 & 1138 & 1134 \\
\hline
\end{tabular}


Table 5 Distribution of IOP peaks by time of the day and diagnosis

\begin{tabular}{|c|c|c|c|c|c|c|c|}
\hline \multirow[b]{2}{*}{ Diagnosis } & \multicolumn{2}{|c|}{ Time of reading } & 3 & 4 & 5 & \multicolumn{2}{|l|}{6} \\
\hline & $\%$ & $\%$ & $\%$ & $\%$ & $\%$ & $\%$ & $(n)$ \\
\hline $\begin{array}{l}\text { Normal } \\
\text { OAG } \\
\text { OHT } \\
\text { CACG } \\
\text { Aphakic/pseudophakic } \\
\text { Total }\end{array}$ & $\begin{array}{l}40 \cdot 5 \\
37 \cdot 9 \\
45 \cdot 7 \\
32 \cdot 5 \\
35 \cdot 1 \\
41 \cdot 4\end{array}$ & $\begin{array}{l}22 \cdot 6 \\
24 \cdot 3 \\
24 \cdot 0 \\
26 \cdot 3 \\
18 \cdot 9 \\
23 \cdot 9\end{array}$ & $\begin{array}{l}19 \cdot 0 \\
12 \cdot 9 \\
11 \cdot 7 \\
10 \cdot 0 \\
18 \cdot 9 \\
13 \cdot 0\end{array}$ & $\begin{array}{r}6 \cdot 0 \\
12 \cdot 9 \\
9 \cdot 1 \\
11 \cdot 3 \\
13 \cdot 5 \\
10 \cdot 0\end{array}$ & $\begin{array}{r}9 \cdot 5 \\
10 \cdot 0 \\
7 \cdot 1 \\
17 \cdot 5 \\
8 \cdot 1 \\
9 \cdot 3\end{array}$ & $\begin{array}{l}2 \cdot 4 \\
2 \cdot 1 \\
2 \cdot 3 \\
2 \cdot 5 \\
5 \cdot 4 \\
2 \cdot 4\end{array}$ & $\begin{array}{r}(84) \\
(140) \\
(350) \\
(80) \\
(36) \\
(690)\end{array}$ \\
\hline
\end{tabular}

Figure 1 Distribution of peaks by diagnosis and time of readings. Time of readings: (1) 7.45 am until $9.00 \mathrm{am} ;$ (2) 9.45 am unti $11.30 \mathrm{am} ;$ (3) $11.30 \mathrm{am}$ until $2.00 \mathrm{pm}$; (4) $2.00 \mathrm{pm}$ until $4.00 \mathrm{pm} ;(5) 4.00 \mathrm{pm}$ until $5.30 \mathrm{pm}$; (6) $5.30 \mathrm{pm}$ until $7.00 \mathrm{pm}$

$(\times)$ normal, $(+) O A G$,

(*) OHT, (口) CACG,

(৩) aphakic/pseudophakic

Distribution of troughs by diagnosis and time of readings. Time of readings: (1) 7.45 am until $9.00 \mathrm{am} ;$ (2) 9.45 am until $11.30 \mathrm{am} ;$ (3) $11.30 \mathrm{am}$ until $2.00 \mathrm{pm}$; (4) $2.00 \mathrm{pm}$ until $4.00 \mathrm{pm} ;(5) 4.00 \mathrm{pm}$ until $5.30 \mathrm{pm}$;(6) $5.30 \mathrm{pm}$ until $7.00 \mathrm{pm}$

(×) normal, $(+) O A G$

(*) OHT, (口) CACG,

(৩) aphakic/pseudophakic.

Time of Readings

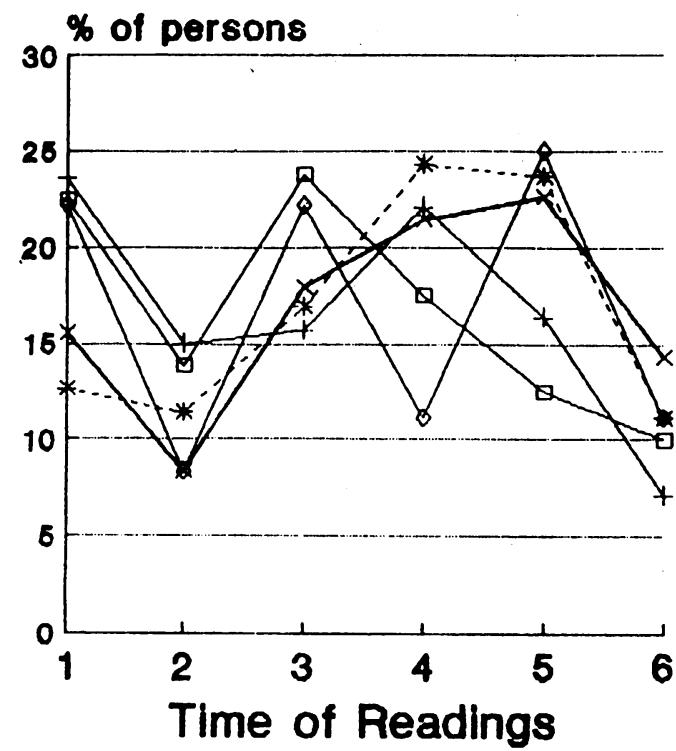

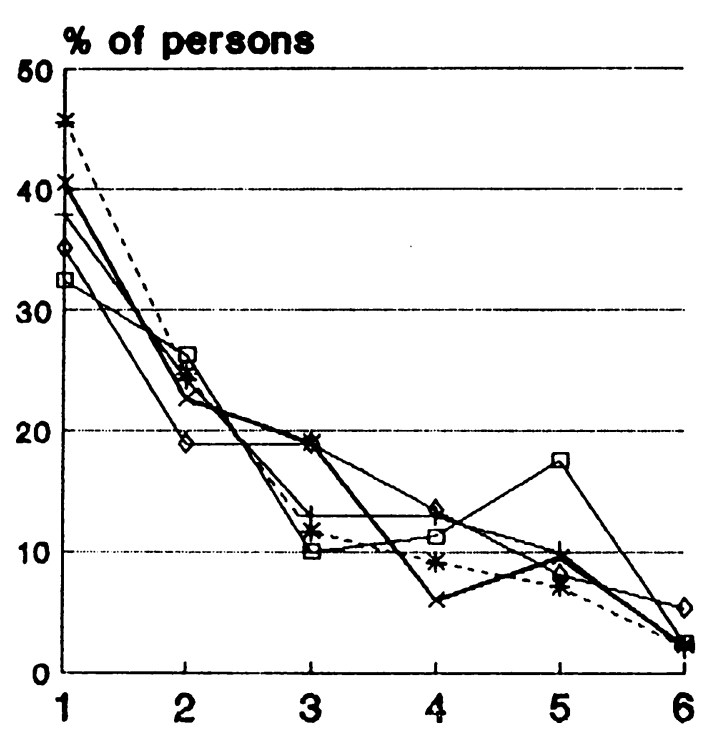

Table 6 Distribution of IOP troughs by time and diagnosis

\begin{tabular}{|c|c|c|c|c|c|c|c|}
\hline \multirow[b]{2}{*}{ Diagnosis } & \multicolumn{2}{|c|}{ Time of reading } & 3 & 4 & 5 & \multicolumn{2}{|l|}{6} \\
\hline & $\%$ & $\%$ & $\%$ & $\%$ & $\%$ & $\%$ & $(n)$ \\
\hline $\begin{array}{l}\text { Normal } \\
\text { OAG } \\
\text { OHT } \\
\text { CACG } \\
\text { Aphakic/pseudophakic } \\
\text { Total }\end{array}$ & $\begin{array}{l}15 \cdot 5 \\
23 \cdot 6 \\
12 \cdot 6 \\
22 \cdot 5 \\
22 \cdot 2 \\
16 \cdot 8\end{array}$ & $\begin{array}{r}8 \cdot 3 \\
15 \cdot 0 \\
11 \cdot 4 \\
13 \cdot 8 \\
8 \cdot 3 \\
11 \cdot 8\end{array}$ & $\begin{array}{l}17 \cdot 9 \\
15 \cdot 7 \\
16 \cdot 9 \\
23 \cdot 8 \\
22 \cdot 2 \\
17 \cdot 8\end{array}$ & $\begin{array}{l}21 \cdot 4 \\
22 \cdot 1 \\
24 \cdot 3 \\
17 \cdot 5 \\
11 \cdot 1 \\
22 \cdot 0\end{array}$ & $\begin{array}{l}22 \cdot 6 \\
16 \cdot 4 \\
23 \cdot 7 \\
12 \cdot 5 \\
25 \cdot 0 \\
20 \cdot 9\end{array}$ & $\begin{array}{r}14 \cdot 3 \\
7 \cdot 1 \\
11 \cdot 1 \\
10 \cdot 0 \\
11 \cdot 1 \\
10 \cdot 6\end{array}$ & $\begin{array}{r}(84) \\
(140) \\
(350) \\
(80) \\
(36) \\
(690)\end{array}$ \\
\hline
\end{tabular}

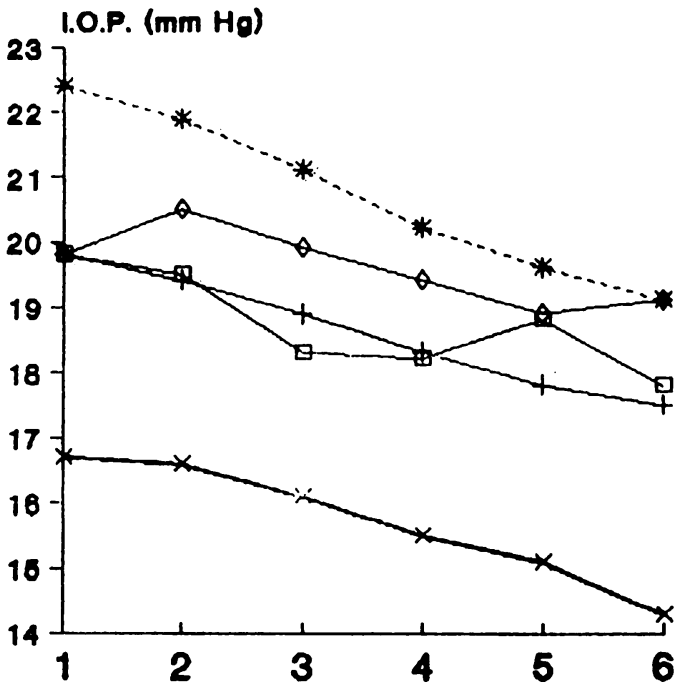

Time of Readings

Figure 3 Mean IOP by diagnosis and time of readings. Time of readings: (1) 7.45 am until 9.00 am; (2) 9.45 am until $11.30 \mathrm{am}$; (3) $11.30 \mathrm{am}$ until $2.00 \mathrm{pm}$; (4) 2.00 pm until $4.00 \mathrm{pm} ;$ (5) $4.00 \mathrm{pm}$ until $5.30 \mathrm{pm}$; (6) $5.30 \mathrm{pm}$ until $7.00 \mathrm{pm} .(\times)$ normal, $(+) O A G,(*) O H T,(\square) C A C G$ ( $)$ aphakic/pseudophakic.

minus lowest IOP) during the DC is shown in Table 7. While the mean IOP range for normals was $5.0 \mathrm{~mm} \mathrm{Hg}$ it was $5.8 \mathrm{~mm} \mathrm{Hg}$ for OAG and CACG and $6.8 \mathrm{~mm} \mathrm{Hg}$ for OHT. These differences were found to be statistically significant $(\mathrm{p}<0 \cdot 001)$.

The type of treatment the patients were receiving at the time of the DC was not associated with the distribution of peaks and troughs. It was however associated with the range of diurnal IOP fluctuation as expressed by the mean range of IOP: patients on $\beta$ blockers had a lower mean IOP range than those on other types of medication (Table 8). This small difference reached statistical significance $(p=0 \cdot 019)$.

Analysis of the patients' age, sex, the presence and type of diabetes (insulin treated vs noninsulin treated), and the season of the year (warm - May through October vs cold - November through April), had no effect on any of the parameters examined: time of peak, time of trough, and range of IOP.

\section{Table 7 Mean of IOP fluctuation by diagnosis groups}

\begin{tabular}{lllr}
\hline Diagnosis & $m m \mathrm{Hg}$ & \multicolumn{1}{c}{$S D$} & \multicolumn{1}{c}{$n$} \\
\hline Normal & 5.0 & 2.7 & 84 \\
OAG & 5.8 & 2.9 & 140 \\
OHT & 6.8 & 3.2 & 350 \\
CACG & 5.9 & 3.4 & 88 \\
Aphakic/pseudophakic & 5.8 & 2.9 & 37 \\
\hline
\end{tabular}

$F=7.03 ; p<0.001$.

Table 8 IOP range of fluctuation by type of treatment (all diagnoses)

\begin{tabular}{lll}
\hline & \multicolumn{2}{l}{ IOP $\mathrm{mm} \mathrm{Hg}$} \\
\cline { 2 - 3 } Type of treatment & Mean & $S D$ \\
\hline No treatment & $6 \cdot 2$ & $2 \cdot 7$ \\
$\beta$ blocker only & $5 \cdot 5$ & $2 \cdot 6$ \\
$\beta$ blocker plus other & $5 \cdot 5$ & $2 \cdot 7$ \\
Other except $\beta$ blocker & $6 \cdot 3$ & $3 \cdot 4$ \\
\hline
\end{tabular}




\section{Discussion}

Identifying the peak IOP in each individual's follow-up is the main reason for conducting DCs. Worthen ${ }^{7}$ reviewed the literature and found that both in normals and glaucomatous eyes the peak IOP occurred before $2.00 \mathrm{pm}$. Such a pattern was also found in a glaucoma screening programme scheduled for mornings and afternoons: the morning screening yielded $17 \%$ elevated IOP while the afternoon only $9 \%$. Furthermore re-examination of the IOP in the afternoon after the morning reading showed higher values in only $10 \%$ of cases but lower values in $51 \% .^{8}$

As stated earlier most of the studies quoted suffered from several limitations and possibly for that reason there is the continued practice of performing diurnal pressure curves, often with patients entering hospital for this purpose.

There are several advantages to our study. The first is that it included all persons who had a diurnal curve recorded in their glaucoma file and did not include a selected population. We have no reason to think that this population differs from others in need of DC evaluation. Second, the DC evaluation was conducted in an outpatient setting with minimal interference with the patients' life style and treatment regimen. In addition the IOP measurements were conducted using the modern standards generally accepted today in glaucoma practice.

We realise that starting the DC in the clinic around 8 am is less than ideal: there are reports claiming the highest IOP occurs immediately after waking. ${ }^{9}$ It is also possible that the home tonometry, as advocated by Zeimer, ${ }^{10}$ covers a larger portion of the 24 hour cycle. Nevertheless the widely employed practice today is IOP measurement by ophthalmologists in their offices, and therefore the information collected and presented here is still useful.

The clinical importance of our finding, that two thirds of the peak IOPs occur before noon and only $30 \%$ during the following 7 hours in this large series, raises a serious question as to the necessity of extending the DC hours beyond $4.00 \mathrm{pm}$. More important it emphasises the fact that solitary IOP examination taken in the late afternoon or early evening may miss up to $97 \%$ of IOP peaks! Bearing in mind that some glaucoma clinics are held in the afternoon and in many private practices the patients prefer the late appointments (after business hours, traffic rush, etc), this finding indicates that a revision of the timetable for IOP examination in the glaucoma population may be warranted.

The range of IOP fluctuation during the DCs in the various diagnostic groups is slightly different from those reported in earlier studies. The range of fluctuations we found in patients with various types of glaucoma was smaller than in ocular hypertensives. One of the reasons for this finding is that all glaucoma patients seen at the glaucoma clinic are referrals from ophthalmologists in the general eye clinics where medication is started immediately at time of the diagnosis. On the other hand many of the ocular hypertensives are followed carefully but left untreated. Out of 360 first (RE) DCs performed on ocular hypertensives only $21 \%$ were on treatment. The range of fluctuation among those not treated was only slightly higher than those treated $(6.8 \mathrm{~mm} \mathrm{Hg}$ versus $6.5 \mathrm{~mm} \mathrm{Hg}$ respectively).

The finding that topical $\beta$ blockers flatten the diurnal IOP curve has been reported before in studies using timolol ${ }^{112}$ and both timolol and levobunolol ${ }^{13}$ on smaller groups of patients; in the present study of DCs of the 273 treated patients $40.6 \%$ were receiving timolol (alone or in combination with other IOP lowering drugs) and $59.4 \%$ were on medication(s) other than $\beta$ blockers. Due to the large number of cases the small $(1 \mathrm{~mm} \mathrm{Hg})$ difference between the mean IOP in the subgroups reached statistical significance. However the clinical importance of this finding is questionable.

We did not find associations between age, sex, the presence of diabetes, and the IOP parameters examined (time of peak, trough, and daily fluctuation). Moreover examination of the 411 patients with multiple DCs throughout the year did not detect any seasonal variations in the pattern of their IOP behaviour.

This paper has been partly presented at the Association for Research in Vision and Ophthalmology meeting, Sarasota, FL May 1990.

1 Drance SM. The significance of the diurnal tension variations in normal and glaucomatous eyes. Arch Ophthalmol 1960; 64: in normal and 501 .

2 Katavisto $M$. The diurnal variations of ocular tension in glaucoma. Acta Ophthalmol 1964; 78: 1-130.

3 Kitazawa Y, Horie T. Diurnal variation in intra-ocular pressure in primary open angle glaucoma. Am f Ophthalmol 1975; 79: in prima.

4 Worthen DM. Effect of pilocarpine drops on the diurnal intra-ocular pressure in patients with glaucoma. Invest intra-ocular pressure in pate

5 Drance SM. Diurnal variation of intra-ocular pressure in treated glaucoma: significance in patients with chronic treated glaucoma: significance in patients with ch
simple glaucoma. Arch Ophthalmol 1963; 70: 302-11.

6 Henkind P, Leitman M, Weitzman E. The diurnal curve in man: new observations. Invest Ophthalmol 1973; 12: 705-7. 7 Worthen, DM. Intra-ocular pressure and its diurnal variation. In: Heilman K, Richardson KT, eds. Glaucoma-conceptions In: Heilman K, Richardson KT, eds. Glaucoma -concep
of a disease. Stuttgart: Georg Thieme, 1978: 54-66.

8 Lennon RG. Turnbull CD. Diurnal intra-ocular pressure variation in a glaucoma screening program. Arch Ophthalmol variation in a glauco

9 Zeimer RC, Wilensky JT, Gieser DK. Presence and rapid decline of early morning intraocular pressure peaks in decline of early morning intraocular pressure pe
glaucoma patients. Ophthalmology $1990 ; 97: 547-50$.

10 Zeimer RC, Wilensky JT, Gieser DK, et al. A pplication of a self Zeimer RC, Wilensky JT, Gieser DK, et al. Application of a self
tonometer to home tonometry. Arch Ophthalmol 1986; 104: tonome

11 Reynolds PM. The effect of topical timolol maleate on the diurnal curve - a preliminary report. Res Clin For 1980; 2 diurnal

12 David R, Sachs U. Long-term follow-up of patients with various types of glaucoma and ocular hypertension.

13 Silverstone DE, Arkfield D, Cowan G, Lue JC, Novack GD. Long term diurnal control of intra-ocular pressure with
levobunolol and timolol. Glaucoma 1985; 7: 138-40. 